\title{
Cells Electrical Characterization: Dielectric Properties, Mixture, and Modeling Theories
}

\author{
Nida Nasir $(1)$ and Mahmoud Al Ahmad \\ Electrical Engineering Department, United Arab Emirates University, Al Ain, Abu Dhabi 15551, UAE \\ Correspondence should be addressed to Nida Nasir; nida.nasir@uaeu.ac.ae
}

Received 3 November 2019; Accepted 30 December 2019; Published 24 January 2020

Academic Editor: Abdullah A. Kendoush

Copyright ( $\odot 2020$ Nida Nasir and Mahmoud Al Ahmad. This is an open access article distributed under the Creative Commons Attribution License, which permits unrestricted use, distribution, and reproduction in any medium, provided the original work is properly cited.

\begin{abstract}
Electrical detection of biotic materials and their properties is always crucial in Biomedical Engineering. It emphasizes elaborate analysis of a certain disease diagnosis using electrical means which includes the study of electrical properties followed by detection, identification, and quantification of biotic entities. Proper and early detection of cells, which can be normal or cancerous, holds never-ending demand. This review emphasizes the electrical characterization methods in modeling and classification of cell properties. Moreover, standard methods have been highlighted and discussed to yield performance analysis. This study suggests that techniques presented for single-cell analysis (SCA) are always precise and hold great scope compared to those for cell mixture. SCA plays a promising role in disease diagnosis and treatment planning, as it not only detects the cells but also helps in identification. Distinct electrical-based cell detection techniques are highlighted, along with the pros and cons of various SCA devices. The content, in terms of methodologies and available techniques, of this review paper is useful to attract researchers working in this area.
\end{abstract}

\section{Introduction}

Over the years, many studies have been performed which extract biological parameters from electrical signals, such as those from the nervous system (resting and membrane potential) [1], muscles (electromyography or EMG) [2], heart (electrocardiogram or ECG) [3], and from other parts of the body that are used to analyze the human body and its behavior. Moreover, electrical signals from cancer cell lines [4], normal cells [5], viruses [6], DNA [7], exosomes [8], blood [9], etc. have been widely used for the detection of various diseases. Single-cell parameters like cell and cytoplasm conductivity, relaxation frequency, and membrane capacitance are significant [10].

With the progression of CMOS, MEMS, BioMEMS, and other technologies, the popularity of this field has surged. For building smaller electronic devices and gadgets, the electrical characterization of materials plays a pivotal role. Thus, this tool has become a crucial technique in numerous fields, such as medicine, science, and engineering. In this review, a generalized description of the famous trends has been highlighted along with various types of electrical properties of the cells which are crucial in the biomedical engineering field. Some of the biological properties of the normal and cancer cells have been depicted in Table 1, which play a crucial role in electrical characterization in cancer research.

This review study focuses on the electrical properties of cells such as dispersions, polarization, and relaxation. Moreover, this study shows how Maxwell's mixture theory and modeling the dielectric attributes of the cells help in electrical characterization and thereby play a fundamental part in illness diagnosis, planning, and outcome.

\section{Electrical Characterization}

There are numerous biological materials that can be characterized using electrical methods. These materials can be cells, viruses, DNA, exosomes, blood, etc. Many techniques such as scanning tunneling microscopy (STM) [11], nanotechnology [12], carbon nanotube networks $[13,14]$, microstrip cavity resonant measurement [15], dielectrophoretic impedance 
TABLE 1: Biological properties of normal and cancer cells.

\begin{tabular}{lcc}
\hline & Normal cells & Cancer cells \\
\hline Shape & Regular, small & Irregular, large \\
Cytoplasm & Relatively large volume & Relatively small volume \\
Nucleus & Proportionate size, uniform & Larger and darker, variable \\
Growth & In control, systematic & Fast and high division \\
Maturation & Mature through cell differentiation & Does not mature \\
Visibility & Visible to immune cells, with ID & Invisible to immune cells \\
Blood supply & Angiogenesis during repair & Tumor angiogenesis \\
Oxygen & Required & Mostly not required \\
Glucose & Sometimes & Always \\
Energy efficiency & $95 \%$ & $5 \%$ \\
ATP & 36 units & 2 units \\
Environment & Alkaline & Acidic \\
Nutrition preferences & Fat, ketone, glucose & Glucose \\
\hline
\end{tabular}

measurement (DEPIM) $[16,17]$ are there to detect and identify these viruses. Moreover, for DNA characterization, there are various techniques such as carbon nanoparticles (CNPs) [18-20], field effect transistors (FETs) [21, 22], cyclic voltammetry $[23,24]$, molecular wire $[25,26]$, graphene quantum $[27,28]$, and dielectrophoresis $[29,30]$. Biophysical properties give early indications of sickness or atypical state of the body, which makes promising markers for detecting various cancers [31-35], bacteria [36-40], toxins [41, 42], and tissues status [43-45].

Cell techniques can be classified as single-cell analysis and cell characterization. For single-cell analysis (SCA), patch-clamp and nanoprobes had been used; however, the latest microfluidics, microelectrical impedance spectroscopy, and electrorotation techniques are quite promising [46]. Fast emerging technologies have been developed and advanced by the scientists in the past few decades, to study the biophysical properties of cells and to make extensive influences on biology and the clinical research field. For the breast cancer detection, available techniques are X-ray mammography [47], magnetic resonance imaging [48], ultrasound waves $[49,50]$, positron emission tomography [51], and ultrawideband techniques [52]. A comparison of these techniques has been done in Table 2, depicting sensitivity, specificity, positive predicted value, and accuracy.

The electrical traits of cells provide vision and crucial data to help in the insights of the complicated physiological states. Cells that undergo aberrations or get any kind of infections might exhibit different ion movements [53] and change in conductivity and resistance of cytoplasm [54-57] along with distortions in shape and size [58]. For example, malaria causes infection in RBCs by Plasmodium falciparum, which leads to deformability [34, 59, 60]. Electrical traits are beneficial in cell study for quantification, separation, trapping, and single-cell characterization, especially in terms of precise estimation, compactness, and ease of operation.

Linkov et al. provide various comparations of nanomaterials and their techniques along with characterization of advantages and limitations [71]. In his detailed study, they include comparisons of scanning electron microscopy, transmission electron microscopy, scanning tunneling microscopy (STM), atomic force microscopy (AFM) or scanning force microscopy, dynamic light scattering and fluorescence correlation spectroscopy, absorption spectroscopy, X-ray diffraction, and X-ray photoelectron spectroscopy. A comparison of these techniques has been done in Table 3, depicting their problems. For tissue engineering, various types of electric fields used for the cell manipulation, such as electrical [61, 62], optical [63-66], ultrasound $[67,68]$, and magnetic $[69,70]$, are undergoing advancements. A comparison of these techniques has been done in Table 4.

\section{Electrical Properties of Cells}

The electrical-based passive traits of cells were first investigated in 1770s by Henry [72], who found that the current was directly proportional to the voltage and that salt mixtures showed a greater conductivity than normal water. The famous relationship connecting the voltage, current, and resistance was given by Georg Ohm, who formulated the well-known Ohm's law [73]. In 1902, Bernstein [74] combined all of the relevant information about the cell membrane and articulated certain features. First, cells have an electrolyte enclosed by an impermeable membrane that allows the flow of ions. Second, a steady-state potential difference exists across the membrane. Third, the membrane allows potassium ion flow over a certain range of currents and voltages, known as the Nernst diffusion potential. Fourth, living tissue exhibits a relatively high dc resistivity. Höber $[75,76]$ deduced that, at different frequencies, the current path changes; he focused mainly on the current penetration into the conductive part of the cell at higher frequencies. He also developed the concept of $\beta$-dispersion, which describes the phenomenon that the outer membrane of the cell has a high resistivity for $\mathrm{dc}$ and (low-frequency) ac currents, has a very high capacity for collecting ions at its surface. This is known as Maxwell-Wagner interfacial polarization.

Various equivalent circuits have been proposed by many scientists. Figure 1(a) shows the equivalent circuit of RBCs developed by Philippson [77], where $r$ and $R$ are the resistances of the membrane and cytoplasm, respectively, 
TABLE 2: Breast cancer detection techniques.

\begin{tabular}{lcccc}
\hline Diagnostic procedure & Sensitivity (\%) & Specificity (\%) & Positive predicted value (\%) & Accuracy (\%) \\
\hline Mammography & 68 & 75 & 86 & 70.2 \\
MRI & 94.4 & 26 & 73.6 & 73 \\
Ultrasound & 83.1 & 34 & 73.4 & 68 \\
Clinical checkup & 50.4 & 92.1 & 94.3 & 64 \\
\hline
\end{tabular}

TABle 3: Techniques for nanomaterial characterization [71].

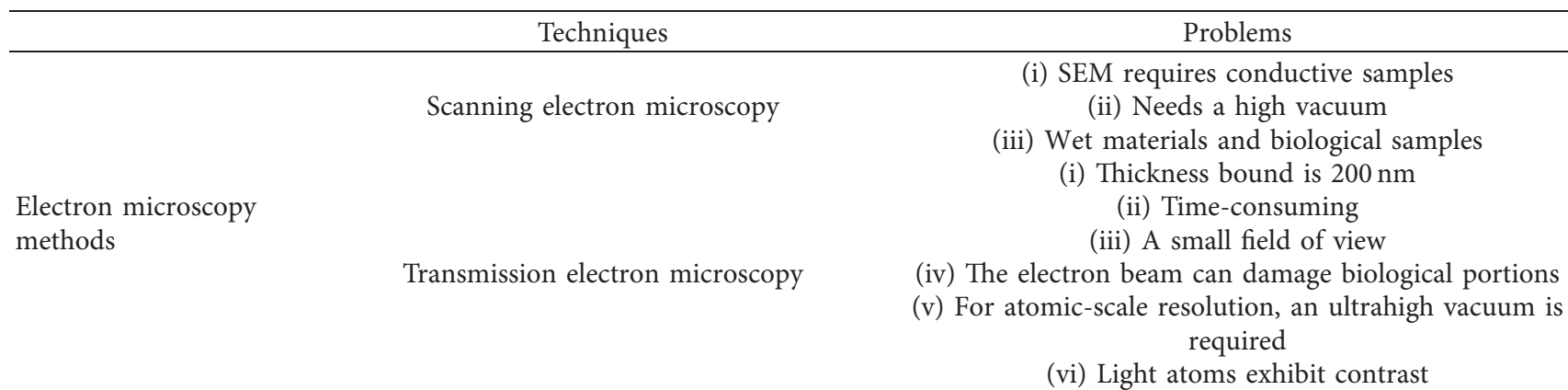

Scanning tunneling microscopy (STM)

Scanning probe microscopy methods

Atomic force microscopy (AFM) or scanning force microscopy

Dynamic light scattering and fluorescence correlation spectroscopy

Optic methods

Absorption spectroscopy

X-ray diffraction

X-ray methods

X-ray photoelectron spectroscopy (i) Conductive samples

(ii) Noise reduction is required

(i) Small scan image size

(ii) Scanning speed is restricted

(iii) A slow rate of scanning leads to thermal drift

(iv) Images affected by hysteresis property of the piezoelectric material

(i) Average particle size, error when larger atoms or impurity elements are present in a sample

(ii) In the nanoparticle sample, the analysis is biased toward highly refractile particles

(i) Error due to scattering via solid particles in heterogeneous samples

(ii) Restricted to turbid samples

Broad peaks from small crystals, making it problematic to verify the crystalline orientation

(i) Errors in the chemical analysis for heterogeneous exteriors (ii) Degradation during the study (iii) A high vacuum is required

TABLE 4: Electric fields used for cell manipulation.

\begin{tabular}{|c|c|c|c|c|c|}
\hline $\begin{array}{l}\text { Physical force } \\
\text { field }\end{array}$ & Spatial resolution & Field effect on the cell viability & $\begin{array}{l}\text { Variation directly in the } \\
\text { growth medium? }\end{array}$ & $\begin{array}{l}\text { Number of cells } \\
\text { controlled at once }\end{array}$ & $\begin{array}{l}\text { Typical } \\
\text { volume }\end{array}$ \\
\hline Optical & $\begin{array}{l}\text { Very high, in } \\
\text { nanometers }\end{array}$ & (i) Low heating & Yes & Few hundreds of cells & $\mathrm{pL}$ \\
\hline Electrical & $\begin{array}{l}\text { Typically in } \\
\text { micrometers }\end{array}$ & $\begin{array}{l}\text { (i) Heating } \\
\text { (i) Breaking down of the } \\
\text { membrane at high fields }\end{array}$ & Tough & $\begin{array}{l}\text { Single cell to millions of } \\
\text { cells }\end{array}$ & $\mu \mathrm{L}-\mathrm{mL}$ \\
\hline Magnetic & $\begin{array}{l}\text { Typically in } \\
\text { micrometers }\end{array}$ & $\begin{array}{c}\text { (i) Needs magnetizable cells; } \\
\text { otherwise, negligible }\end{array}$ & Yes & $\begin{array}{l}\text { Single cell to millions of } \\
\text { cells }\end{array}$ & $\mu \mathrm{L}-\mathrm{mL}$ \\
\hline Ultrasound & $\begin{array}{l}\text { Low, in tens of } \\
\text { micrometers }\end{array}$ & Slight & Yes & Multimillions of cells & $\mathrm{mL}$ \\
\hline
\end{tabular}

while $C$ is the capacitance of the membrane. As shown in Figure 1(b), Fricke and Morse proposed an equivalent circuit of RBC suspensions, where $R_{0}$ is the resistance around the cell and $R_{i}$ is the resistance of the cytoplasm [78]. In addition,
Cole and Baker discovered an inductive reactance within the membrane structure [79] and developed the equivalent circuit depicted in Figure 1(c). The components $R, C$, and $L$ were determined to have values of $1 \mathrm{k} \Omega \mathrm{cm}^{2}, 1 \mu \mathrm{F} / \mathrm{cm}^{2}$, and 


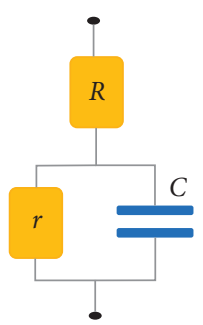

(a)

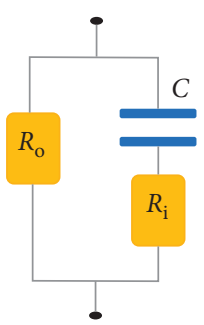

(b)

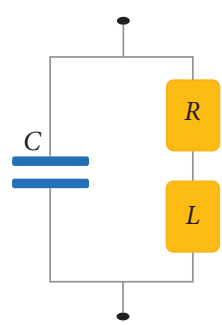

(c)

Figure 1: Equivalent circuits proposed by (a) Philippson, (b) Fricke and Morse, and (c) Cole and Baker.

$0.2 \mathrm{H} \mathrm{cm}^{2}$, respectively. The resistance and capacitance of the cell can be quantified by introducing a parameter $(\phi)$ that signifies the ratio of the actual area of the cell (or nucleus) membrane to the area of the membrane $\left(4 \pi r^{2}\right)$ formed by smooth and spherical layers of the cytoplasm or nucleoplasm [80]. The measured membrane capacitance $\left(C_{m}\right)$ and membrane resistance $\left(R_{m}\right)$ are as follows:

$$
\begin{gathered}
C_{m}=\phi C_{0}, \\
R_{m}=\frac{1}{\phi} R_{0},
\end{gathered}
$$

where $C_{0}$ and $R_{0}$ represent the associated values for a perfectly smooth membrane, corresponding to $\phi=1$.

There are various electrical properties related to biological cells that not only help in better understanding of the characteristics of cells but also help in acquiring indications about the abnormalities within them. Some of the electrical properties are the dielectric dispersions $(\alpha, \beta, \gamma$, and $\delta$ dispersions), polarization (electronic, atomic, and orientation polarization), and relaxation (static and dynamic permittivity). These aspects are explained as follows.

3.1. Dielectric Dispersions. The dielectric properties of the cells at the cellular and molecular levels can be determined by the interaction of EM radiation. The relative permittivity $\left(\varepsilon_{r}\right)$ can reach up to $10^{6}$ to $10^{7}$ below $100 \mathrm{~Hz}$. The permittivity variation at high frequencies can be described via $\alpha, \beta, \gamma$, and $\delta$ dispersions [81]. The dispersions indicate the dielectric relaxations that arise from the polarization mechanisms that occur in complex biological environments (Figure 2).

The step changes in relative permittivity $\left(\varepsilon_{r}\right)$ over the frequency spectrum are known as dispersions, which occur because of the loss of certain polarization modes. $\alpha$-dispersion arises from the ions tangential flow across the cell surfaces; $\beta$-dispersion occurs due to the accumulation of the charges at the cell membranes because of the Maxwell-Wagner interfacial polarization; $\delta$-dispersion occurs from the dipolar movements of large molecules and relaxation of the bound-water (BW); and $\gamma$-dispersion is related to the dipolar rotation of smaller molecules, mainly water [82]. The $\alpha, \beta, \gamma$, and $\delta$ dispersions consequently are described by the dielectric relaxation and frequency range. These are mainly characterized by the total dielectric decrements, i.e., $\Delta \varepsilon_{\alpha}, \Delta \varepsilon_{\beta}, \Delta \varepsilon_{\gamma}$, and $\Delta \varepsilon_{\delta}$, respectively.

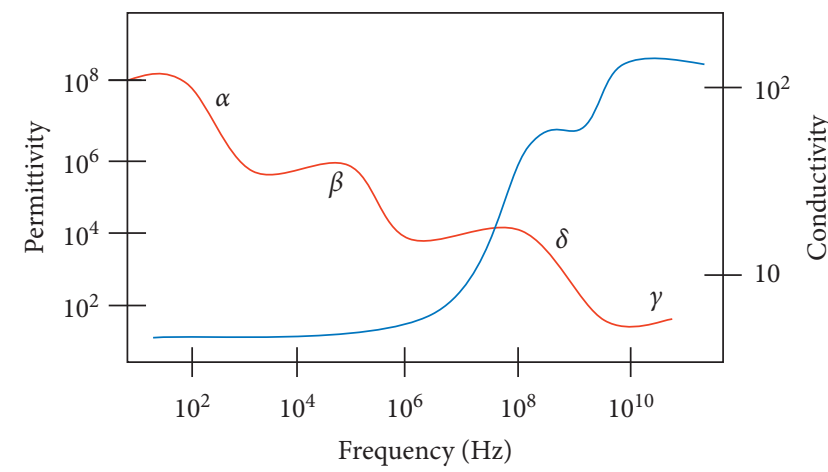

FIgUre 2: Permittivity and conductivity over the frequency spectrum, depicting the $\alpha, \beta, \gamma$, and $\delta$ dispersions.

3.1.1. Alpha Dispersion. The $\alpha$ dispersion occurs in a lowfrequency range, i.e., $10 \mathrm{~Hz}$ to $10 \mathrm{kHz}$, while the relaxation time $(\tau)$ is $6 \mathrm{~ms}$. This mode is categorized by a very high permittivity increment and very high dielectric decrement values $\left(\Delta \varepsilon_{\alpha} \approx 10^{6}\right)$. This dispersion occurs near the cell membrane where the movements of charged particles are limited. The cell membrane is a complex structure consisting of phospholipids, cholesterol, proteins, and carbohydrates. There is a potential difference (approximately $60-70 \mathrm{mV}$ ) between the intracellular and extracellular media due to the ions which are distributed around the membrane (about $10 \mathrm{kV} / \mathrm{mm}$ ).

The phospholipids and cholesterol maintain the fluidity of the cell membrane whole proteins help in ion and signal transport. Penetration into the membrane is possible from the ion channels and membrane-spanning protein. However, Kramers-Kronig [83-85] predicted that the change in conductivity is about $5 \mathrm{mS} / \mathrm{m}$ for a $10^{6}$ permittivity increment, with a relaxation frequency of $100 \mathrm{~Hz}$. This shows that, with a large permittivity increment, there is a very small corresponding conductivity decrement.

3.1.2. Beta Dispersion. The $\beta$-dispersion arises within the frequency of $10 \mathrm{kHz}-10 \mathrm{MHz}$ with a relaxation time approximately $300 \mathrm{~ns}$. The cellular membranes and other intracellular bodies become charged (capacitive), leading to this dispersion type. The cell membranes are electrically shorted, while the current can penetrate through the cytoplasm. This penetration decreases the impedance and leads to the $\beta$-dispersion or interfacial polarization or the 
Maxwell-Wagner relation. This effect occurs at the interface of membrane-electrolyte structures, which have two different dielectrics, leading to the formation of charges. The polarization magnitude depends on the conductivity, permittivity, and structure of the distinct intracellular components. With increasing frequency, the number of resistive elements is nullified by their related parallel capacitances, making the intracellular structures more electrically similar. Usually, blood shows interfacial polarization at the $3 \mathrm{MHz}$ frequency with a $50 \mathrm{~ns}$ relaxation time and $\Delta \varepsilon_{\alpha} \approx 2000$. This effect arises due to charging cell membranes through the electrically conductive cytoplasm cell. The effect is an extension of $\beta$-dispersion and hence is called $\beta_{1}$ dispersion [86]. Certain tissues have larger cell sizes and hence exhibit larger permittivity values than those of blood.

3.1.3. Delta Dispersion. Some protein solutions exhibit $\delta$-dispersion, which lies between the $\beta$ - and $\gamma$-dispersions. If present, the effect falls within the frequency of 0.1 to $5 \mathrm{GHz}$, and comparatively, its magnitude is small. $\delta$-dispersion was first categorized in a study by Pethig [87] and was credited to the dipolar moments of proteins and other large molecules such as biopolymers, cellular organelles [88], and proteinbound water [89]. Mechanisms such as the relaxation of BW (dipolar) or molecules side chains and counterion diffusion in minor charged regions are possible origins of $\delta$-dispersion. The total water content of tissue consists of water in both states, i.e., free and bound. The BW is rotationally hindered and has a relaxation frequency lower than that of the free water (approximately 50-150 times lower).

3.1.4. Gamma Dispersion. In 1989, Foster and Schwan discovered $\gamma$-dispersion [90], which occurs due to the presence of water content in the cells and tissues. The dielectric properties of cells and tissues at frequencies above $0.1 \mathrm{GHz}$ depend on the intracellular electrolytes and water (dipole polarization). At frequencies above a few hundred megahertz, the complex permittivity can be decoupled into terms of Cole-Cole and conductivity which are related to the dispersion of water (dipolar) and the electrolytic behavior, respectively, written as

$$
\varepsilon^{*}(\omega)=\varepsilon_{\infty}+\frac{\left(\varepsilon_{S}-\varepsilon_{\infty}\right)}{1+(j \omega \tau)^{(1-\alpha)}}+\frac{\sigma}{j \omega \varepsilon_{0}},
$$

where $\sigma$ is the conductivity from ionic currents and lowfrequency polarization and $\alpha$ is the distribution parameter. $\gamma$-dispersion arises at microwave frequencies of approximately $25 \mathrm{GHz}$ with a relaxation time of approximately $6 \mathrm{ps}$ and a dielectric decrement of $\Delta \varepsilon_{\gamma} \approx 50$.

3.2. Polarization. Polarization is a process that occurs when an electrical field is employed to a dielectric material and a molecular movement can be observed within the structure. Perpendicular to the direction of the applied field, the total charge passing through a unit area within the dielectric material is known as the polarization. The following are the types of polarization [91].
3.2.1. Electronic Polarization $\left(P_{e}\right)$. As the name suggests, electronic polarization occurs due to the displacement of electrons with respect to the atomic nucleons and occurs in atoms in the dielectric material. The duration of the phenomenon is very small $\left(\sim 10^{-15} \mathrm{~s}\right)$, which corresponds to the period of ultraviolet light.

3.2.2. Atomic Polarization $\left(P_{a}\right)$. Atomic polarization occurs due to the shifting of atoms or groups of atoms within the structure. The small duration of the phenomenon corresponds to the period $\left(10^{-13}\right.$ to $\left.10^{-12} \mathrm{~s}\right)$ of infrared light.

3.2.3. Orientation Polarization $\left(P_{o}\right)$. Orientation polarization arises from polar molecules. It occurs in dielectric materials because of the permanent dipoles' rotation. The orientation of the dipoles of the molecules is the same as the applied field direction and depends on the molecule size, viscosity, temperature, and applied field frequency. The duration of the phenomenon $\left(10^{-12}\right.$ to $\left.10^{-10} \mathrm{~s}\right)$ corresponds to the frequency of the microwave region. Thus, the overall polarization $\left(P_{\mathrm{t}}\right)$ is

$$
P_{\mathrm{t}}=P_{\mathrm{a}}+P_{\mathrm{e}}+P_{\mathrm{o}} .
$$

Therefore, the permittivity of the polar materials is higher than that of the nonpolar materials due to the presence of $P_{\mathrm{o}}$.

3.3. Dielectric Relaxation. The theories of dielectric relaxation are based on static permittivity and dynamic permittivity.

3.3.1. Static Permittivity and Its Models. When the constant dipole is there in a dielectric material, then the moment exists in a steady electric field $(F)$ where all polarization can maintain equilibrium. The permittivity of such dielectric materials under this condition is known as the static permittivity [92]. Different models are used to describe the static permittivity, some of which are described below:

(1) Clausius-Mossotti Relation. The Clausius-Mossotti relation expresses the permittivity in terms of the atomic polarizability [93], on the application of $F$ acting on a molecule, which possesses an electric moment $(m)$ :

$$
m=\alpha_{0} F,
$$

where $\alpha_{0}$ is the polarizability of each molecule. The dipole moment may be permanent or induced. The mean moment $\left(M^{\prime}\right)$ which exists in the direction of the $F$ is depicted by the average dipole moment and the displacement of elastically bound charges [94]:

$$
M^{\prime}=\frac{\mu^{2} \cos ^{2} \theta}{K T} F+e . r .
$$

The force $F$ applies a unit positive charge bounded by a small sphere [95]. This force consists of three components: one related to the surface charge density $(\delta)$ of the plates 
$\left(F_{1}\right)$, another one related to external surface polarization $\left(F_{2}\right)$, and the last one related to molecules inside the small sphere $\left(F_{3}\right)$ :

$$
\begin{aligned}
F & =F_{1}+F_{2}+F_{3}, \\
F_{1} & =4 \pi \delta .
\end{aligned}
$$

$F_{2}$ is composed of two sections: the first section is because of the induced charges on the dielectric material toward the conducting plates, while the second section is because of the surface charge of the small spherical cavity:

$$
F_{2}=4 \pi P+\left(\frac{4 \pi P}{3}\right),
$$

where $P$ is the polarization of the medium. A general expression for $F_{3}$ is used in special cases; in a cubic crystal, however, $F_{3}=0$. The total force $F$ is given by

$$
F=4 \pi \delta-4 \pi P+\left(\frac{4 \pi P}{3}\right) .
$$

However, the dielectric displacement is

$$
\begin{aligned}
& D=E+4 \pi P=4 \pi \delta, \\
& F=E+4 \pi P-4 \pi P+\left(\frac{4 \pi P}{3}\right), \\
& F=E+\left(\frac{4 \pi P}{3}\right) .
\end{aligned}
$$

Moreover, the dielectric displacement can be represented as

$$
\begin{aligned}
D & =\varepsilon E, \\
E(1-\varepsilon) & =\left(\frac{4 \pi P}{3}\right), \\
\therefore F & =E+\frac{E(1-\varepsilon)}{3}, \\
F & =E \frac{(\varepsilon+2)}{3} .
\end{aligned}
$$

This relation expresses the coupling between the actual force and electric field from the electrostatic calculations [96]. In polarization, $N_{1}$ is the number of molecules per cubic centimeter:

$$
\begin{aligned}
& P=N_{1} m=N_{1} \alpha_{0} F, \\
& P=N_{1} \alpha_{0}\left(\frac{\varepsilon+2}{3}\right) .
\end{aligned}
$$

By using (11) and (15), the link between the dielectric constant and molecular polarizability $\left(\alpha_{0}\right)$ is obtained:

$$
\frac{(\varepsilon-1)}{(\varepsilon+2)}=\frac{4 \pi}{3} N_{1} \alpha_{0} .
$$

In pure substances, $N_{1}=N_{d} / M$, where the molecular weight, the density, and the number of molecules per mole are represented by $M, d$, and $N$, respectively:

$$
\frac{(\varepsilon-1)}{(\varepsilon+2)} \frac{M}{d}=\frac{4 \pi}{3} N \alpha_{0} .
$$

This relation is known as the Clausius-Mossotti equation $[93,94]$. The RHS of (21) shows the molar polarization $(p)$, which describes the electric properties of the molecule as follows:

$$
p=\frac{4 \pi}{3} N \alpha_{0} .
$$

Using (17) and (18),

$$
p=\frac{(\varepsilon-1)}{(\varepsilon+2)} \frac{M}{d} .
$$

The permittivity depends on the polarization; hence, when the applied field frequency is adequately low, all polarizations increase to the instant value of the field. At increasingly elevated frequencies, there is less polarization, and therefore, the permittivity value decreases with increasing frequency.

(2) Debye Theory of Static Permittivity. To derive the relation for static permittivity, the field at a single molecule is considered by imagining a spherical surface of the molecular dimension in the dielectric medium. Assume that the medium inside the sphere is composed of individual molecules and that outside the sphere lies a medium of homogeneous permittivity. The field at the center of the sphere can be divided into three parts: first, the external charges and applied field; second, the surface polarization charges; and third, the field due to the sphere material. Debye's theory depends on the suppositions that no neighboring forces act on the dipoles and that the field component due to molecules inside the spherical region is zero. With these assumptions, the equation given by Debye is

$$
\frac{\varepsilon_{0}-1}{\varepsilon_{0}+2}=\frac{4 \pi N_{1}\left(\alpha+\left(\mu^{2} / 3 K T\right)\right)}{3 \varepsilon},
$$

where $N_{1}$ is the number of molecules per unit volume, $\alpha$ is polarizability $\left(\alpha=\alpha_{\text {electronic }}+\alpha_{\text {atomic }}\right), \mu$ is the dipole moment, $K$ is Boltzmann constant, $\varepsilon_{0}$ is static permittivity, and $\varepsilon$ is free space permittivity. If the material has molecular weight $M$ and density $p$, then $N_{1}=N_{p} / M$, where $N$ is Avogadro's number. Therefore, (20) can be written as

$$
\frac{\varepsilon_{0}-1}{\varepsilon_{0}+2} \times \frac{M}{p}=\frac{4 \pi N\left(\alpha+\left(\mu^{2} / 3 K T\right)\right)}{3 \varepsilon} .
$$

The LHS is molar polarization. The following inferences have been obtained from Debye's theory [97]. First, the molar polarizability of a nonpolar substance must be fixed and should not be dependent on the temperature and pressure, as the density is directly proportional to the permittivity. Second, in the case of polar materials, the dipolar polarization decreases due to thermal agitation. Third, below a certain temperature $(T)$, the polarization becomes quite large, which makes the molecules align themselves even without the field, and the material turns to ferroelectric: 


$$
T=\frac{4 \pi N \rho \mu}{9 M K \varepsilon} .
$$

Some limitations in (20) arise because of assumptions made to derive the Debye relation. As the validity of the equation is restricted to fluids due to the first assumption, it is not applicable to crystal materials. According to the Debye relation and (22), liquids act as ferroelectric materials at $T<T c$ (where the molar polarizability tends to $M / p$ at $\left(\varepsilon_{0} \longrightarrow \infty\right)$, but ferroelectricity is quite uncommon. This failure of the Debye equation is due to the statement that the force is zero inside the spherical sphere due to the medium, that is most likely invalid.

(3) Kirkwood Theory. Kirkwood considered a material specimen with $N$ dipoles, each having moment $\mu$, within a sphere of volume $V$ inside a uniform external field. Using this assumption, Kirkwood developed an equation for nonpolarizable dipoles:

$$
\frac{(\varepsilon-1)(2 \varepsilon+1)}{3 \varepsilon} \frac{M}{d}=4 \pi N_{A} \frac{g \mu^{2}}{3 K T},
$$

where $g$ is a correlation parameter. When $g$ is unity, the mean moment of the sphere about one molecule is equivalent to the moment of the constant molecule. However, when $g>1$, the dipoles of adjacent molecules are aligned parallel to that of the constant molecule. Moreover, if $g>1$, the dipoles of adjacent molecules are aligned antiparallel with reference to the dipole of the constant molecule. Furthermore, Kirkwood incorporated distortion polarization by attaching the polarizability $(\alpha)$ of each dipole. Thus, Kirkwood's equation is written as

$$
\frac{(\varepsilon-1)(2 \varepsilon+1)}{3 \varepsilon} \frac{M}{d}=4 \pi N_{A}\left[\alpha+\frac{g \mu^{2}}{3 K T}\right] \text {. }
$$

(4) Cole Theory. Cole [94] proposed a theory similar to Kirkwood's for the static permittivity, which differs in the behavior of the direction of polarization. He obtained the expression for static permittivity as follows:

$$
\frac{\left(\varepsilon_{0}-1\right)}{\left(\varepsilon_{0}+2\right)}=\frac{\left(n^{2}-1\right)}{\left(n^{2}+2\right)}+\frac{4 \pi N}{3 v \varepsilon} \times \frac{3 \varepsilon_{0}\left(n^{2}+2\right)}{\left(\varepsilon_{0}+2\right)\left(2 \varepsilon_{0}+n^{2}\right)} \times \frac{g \mu^{2}}{3 K T},
$$

which reduces to

$$
\frac{\varepsilon_{0}-n^{2}\left(2 \varepsilon_{0}+n^{2}\right)}{\varepsilon_{0}\left(n^{2}+2^{2}\right)}=\frac{4 \pi N}{3 v \varepsilon} \times \frac{g \mu^{2}}{3 K T} .
$$

3.3.2. Dynamic Permittivity and Its Models. Putting a dielectric material in an electric field which varies with the applied field frequency and then the frequency-dependent permittivity of the material is called the dynamic permittivity [98]. Various models are used to describe the permittivity in terms of frequency. Some of the most widely used models are described below:
(1) The Debye Model. Debye [97] gave a model for complex permittivity and dielectric loss by the following equation:

$$
\varepsilon^{*}=\varepsilon_{\infty}+\frac{\varepsilon_{0}-\varepsilon_{\infty}}{1+j \omega \tau}
$$

where $\varepsilon^{*}=\varepsilon^{\prime}-j \varepsilon^{\prime \prime}$ is the complex permittivity, $\varepsilon^{\prime}$ is known as the dielectric dispersion, $\varepsilon^{\prime \prime}$ is known as the dielectric loss, $\varepsilon_{0}$ is the static permittivity, and $\varepsilon_{\infty}$ is the permittivity at infinite frequency, $\omega$ is the angular frequency, and $\tau$ is the relaxation time. The physical significance of these equations is that, at the frequency for which $\omega \tau<<1$, i.e., below the absorption curve, equilibrium occurs in a short time compared with that for which the field points in one direction. In this case, the maximum value of permittivity is obtained, and little energy is absorbed. When the frequency approaches that for which $\omega \tau=1$, the field reverses over a time which makes the polarization to reach its maximum value. Thus, the energy absorbed per cycle is maximized. At frequencies for which $\omega \tau>>1$, there is no significant orientation of dipoles in each cycle, and the measured permittivity does not contain a contribution from this polarization.

The variations in $\varepsilon^{\prime}$ and $\varepsilon^{\prime \prime}$ with respect to frequency is shown in Figure 3. These curves are known as the dispersion and absorption curves [99]. The dielectric loss approaches zero for small and large values of frequencies, while it is maximum for $\omega \tau=1$, i.e., $\varepsilon_{\max }^{\prime \prime}=\left(\left(\varepsilon_{0}-n^{2}\right) / 2\right)$ at a frequency $\omega=1 / \tau$, and this parameter falls to half its maximum when $\omega \tau=\left(\left(1+\omega^{2} \tau^{2}\right) / 4\right)$. Another way to represent the experimental result is to construct a diagram by plotting $\varepsilon^{\prime \prime}$ against $\varepsilon^{\prime}$ at the same frequency. The above equations for $\varepsilon^{\prime}$ and $\varepsilon^{\prime \prime}$ are parametric equations for circle. On solving, the following expression has been obtained:

$$
\left(\varepsilon^{\prime}-\frac{\varepsilon_{0}+\varepsilon_{\infty}}{2}\right)^{2}+\varepsilon^{\prime \prime}=\left(\frac{\varepsilon_{0}-\varepsilon_{\infty}}{2}\right)^{2},
$$

which is the equation of a circle with center $\left[\left(\left(\varepsilon_{0}+\varepsilon_{\infty}\right) / 2\right), 0\right]$ and radius $\left.\left(\varepsilon_{0}-\varepsilon_{\infty}\right) / 2\right)$. Figure $3(\mathrm{a})$ shows the Debye semicircle. The demerits of the method are that the frequency is not explicitly shown.

(2) The Cole-Cole Model. The Cole-Cole model describes the experimental observations of many materials with particularly long-chain molecules and polymers, which show a broader dispersion curve and the maximum loss at a lower frequency than would be expected from the Debye relationship. According to Cole and Cole [96], in such cases, the permittivity might follow the empirical equation:

$$
\varepsilon^{*}=\varepsilon_{\infty}+\frac{\varepsilon_{0}-\varepsilon_{\infty}}{1+j \omega \tau^{1-\alpha}}
$$

where depicts the symmetrical distribution parameter of the relaxation time, i.e., $0 \leq \alpha<1$. When $\alpha=0$, the above equation reduces to the Debye equation, as shown in Figure $3(\mathrm{~b})$. The plotted curve of $\varepsilon^{\prime \prime}$ vs $\varepsilon^{\prime}$ obeys the equation of a circle: 


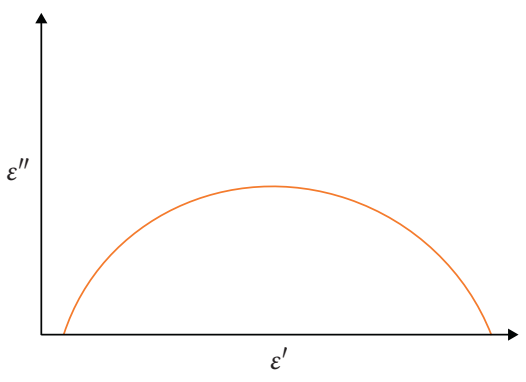

(a)

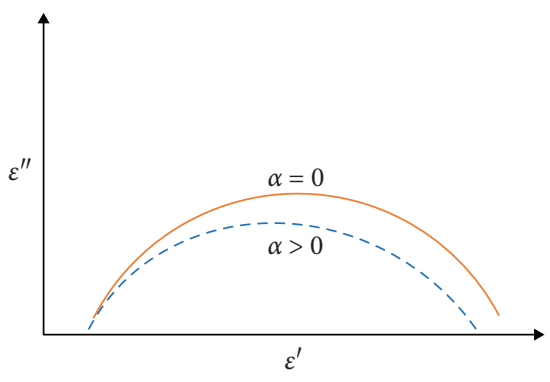

(b)

Figure 3: Illustration of (a) the Debye semicircle and (b) a Cole-Cole plot.

$$
\begin{aligned}
& {\left[\frac{1}{2} \varepsilon_{0}+n^{2}-\varepsilon^{\prime}\right]^{2}+\left[\varepsilon^{\prime \prime}+\frac{1}{2} \varepsilon_{0}-n^{2} \tan \left(\frac{\pi \alpha}{2}\right)\right]^{2},} \\
& \frac{1}{4}\left(\varepsilon_{0}-n^{2}\right) \sec ^{2}\left(\frac{\pi \alpha}{2}\right),
\end{aligned}
$$

with its center at

$$
\left\{\frac{1}{2} \varepsilon_{0}+n^{2},-\frac{1}{2} \varepsilon_{0}-n^{2} \tan \left(\frac{n \alpha}{2}\right)\right\} .
$$

The radius is

$$
\frac{1}{2}\left(\varepsilon_{0}-n^{2}\right) \sec \left(\frac{n \alpha}{2}\right)
$$

\section{Maxwell's Mixture Theory}

A heterogeneous solution is formed when the biological cells are suspended in media and their dielectric traits are usually defined by Maxwell's mixture theory [100]. In the frequency domain, this theory gives an equivalent complex dielectric permittivity of the cells $\left(\widetilde{\varepsilon}_{\text {cell }}\right)$ at a low volume fraction, where cells are considered as a spherical particle spread in a medium:

$$
\widetilde{\varepsilon}_{\text {mix }}=\widetilde{\varepsilon}_{m} \frac{1+2 \varphi \widetilde{f}_{\mathrm{cm}}}{1-\varphi \widetilde{f}_{\mathrm{cm}}},
$$

where $\widetilde{f}_{\mathrm{cm}}=\left(\widetilde{\varepsilon}_{p}-\widetilde{\varepsilon}_{m}\right) /\left(\widetilde{\varepsilon}_{p}+2 \widetilde{\varepsilon}_{m}\right)$ (the Clausius-Mossotti factor) where mix represents the mixture, $p$ represents the particle, $m$ represents the membrane, $\widetilde{\varepsilon}$ is the complex permittivity, $\varepsilon$ is the permittivity, $\sigma$ is the conductivity, $\omega$ is the angular frequency, $\varphi$ is the volume fraction of the cells in the suspension, and

$$
\widetilde{\varepsilon}=\varepsilon-j \frac{\sigma}{\omega} .
$$

However, Maxwell's mixture theory is effective only for low volume fractions, such as $\varphi<10 \%$. Later, Hanai et al. $[101,102]$ extended the theory for all volume fractions, depicted below:

$$
1-\varphi=\left(\frac{\widetilde{\mathcal{\varepsilon}}_{\text {mix }}-\widetilde{\varepsilon}_{p}}{\widetilde{\varepsilon}_{m}-\widetilde{\varepsilon}_{p}}\right)\left(\frac{\widetilde{\varepsilon}_{m}}{\widetilde{\varepsilon}_{\text {mix }}}\right)^{1 / 3} .
$$

For the spherical model of a cell (with single-shell) in suspension, as depicted in Figure 4(a), the complex permittivity of a cell is given as follows [100]:

$$
\widetilde{\varepsilon}_{p}=\widetilde{\varepsilon}_{\text {mem }} \frac{\gamma^{3}+2\left(\left(\widetilde{\varepsilon}_{i}-\widetilde{\varepsilon}_{\text {mem }}\right) /\left(\widetilde{\varepsilon}_{i}+2 \widetilde{\varepsilon}_{\text {mem }}\right)\right)}{\gamma^{3}-\left(\left(\widetilde{\varepsilon}_{i}-\widetilde{\varepsilon}_{\text {mem }}\right) /\left(\widetilde{\varepsilon}_{i}+2 \widetilde{\varepsilon}_{\text {mem }}\right)\right)},
$$

where $\gamma=(R+d) / R$ and $\widetilde{\varepsilon}_{\text {mem }}, \widetilde{\varepsilon}_{i}, R$, and $d$ are the complex permittivity, the cytoplasm permittivity, the radius of the cell, and the membrane thickness, respectively. Therefore, $\widetilde{\varepsilon}_{\text {cell }}$ depends on the cell size, membrane dielectric properties, and internal properties, which are related predominantly to the cytoplasm. The complex bioimpedance $\left(\widetilde{Z}_{\text {mix }}\right)$ cells in the medium is given as follows [100]:

$$
\widetilde{Z}_{\text {mix }}=\frac{1}{j \omega \widetilde{\varepsilon}_{\text {mix }} G},
$$

where $G$ is a geometric constant $(G=A / g), A$ is the area of the electrodes, and $g$ is the gap between them.

4.1. The Electrical Model of a Single Cell. Although the analysis of the equivalent circuit model is generally quite intricate, the membrane conductivity and the cytoplasm permittivity are usually low [103]. Simplified expressions are as follows:

$$
\begin{aligned}
\widetilde{\varepsilon}_{i} & =\frac{-j \sigma_{i}}{\omega}, \\
\widetilde{\varepsilon}_{\text {mem }} & =\varepsilon,
\end{aligned}
$$

where $\sigma_{i}$ is the cytoplasm conductivity and $\varepsilon_{\text {mem }}$ is the membrane permittivity. Inserting the above expressions into (36) and simplifying,

$$
\widetilde{\varepsilon}_{p}=\varepsilon \frac{\gamma^{3}+2\left(\left(-j \sigma_{i} /(\omega-\varepsilon)\right) /\left(\left(2 \varepsilon-j \sigma_{i} / \omega\right)\right)\right)}{\gamma^{3}-\left(\left(-j \sigma_{i} /(\omega-\varepsilon)\right) /\left(\left(2 \varepsilon-j \sigma_{i}\right) / \omega\right)\right)},
$$

$$
\begin{aligned}
\frac{\operatorname{Re}\left[\widetilde{\varepsilon}_{p}\right]+j \operatorname{Im}\left[\widetilde{\varepsilon}_{p}\right]}{\varepsilon}= & \left(\frac{2 b \varepsilon^{2}+a\left(\sigma_{i} / \omega\right)^{2}}{b^{2} \varepsilon^{2}+\left(\sigma_{i} / \omega\right)^{2}}\right) \\
& +j\left(\frac{\varepsilon \sigma_{i} / \omega(2-a b)}{b^{2} \varepsilon^{2}+\left(\sigma_{i} / \omega\right)^{2}}\right),
\end{aligned}
$$

where 


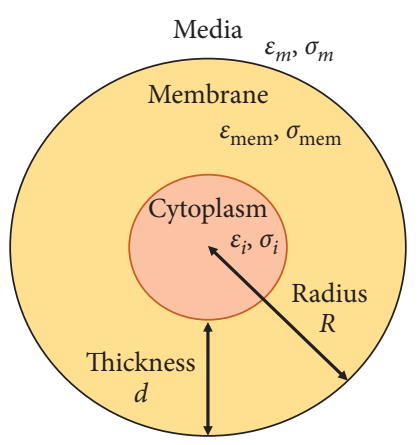

(a)

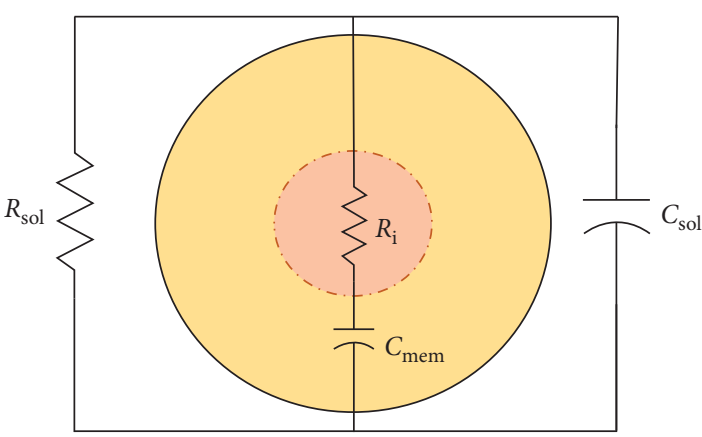

(b)

FIGURE 4: Schematic of the (a) cell model with single-shell, inside suspension; (b) equivalent circuit model of a cell in suspension by Foster and Schwan [90].

$$
\begin{aligned}
& a=\left(\frac{\gamma^{3}+2}{\gamma^{3}-1}\right), \\
& b=\left(\frac{2 \gamma^{3}+1}{\gamma^{3}-1}\right) .
\end{aligned}
$$

The real and imaginary parts of $\dot{\varepsilon}_{p}$ in (40), when divided, produces

$$
\frac{a}{\omega}\left(\frac{\sigma_{i}}{\varepsilon}\right)^{2}-K(2-a b)\left(\frac{\sigma_{i}}{\varepsilon}\right)+2 b \omega=0,
$$

where

$$
K=\left(\frac{\operatorname{Re}\left[\widetilde{\varepsilon}_{p}\right]}{\operatorname{Im}\left[\widetilde{\varepsilon}_{p}\right]}\right) .
$$

Assuming $\sigma_{i} / \varepsilon=1$ and calculating the imaginary part of (40), $\varepsilon_{\text {cell }}$ is

$$
\varepsilon=\left(\frac{b^{2}+\left(1 / \omega^{2}\right)}{(1 / \omega)(2-a b)}\right) \operatorname{Im}\left[\widetilde{\varepsilon}_{p}\right] .
$$

The overall impedance of the suspension is denoted by a parallel combination of resistors and capacitors along with the impedance of the cells. As described in [90], a solo cell is equivalent to a cytoplasmic resistance $\left(R_{i}\right)$ in series with a membrane capacitance $\left(C_{\text {mem }}\right)$, as manifested in Figure 4(b). The simplified cell parameters values (based on frequency) are decided by the cell traits, medium traits, cell size, volume fraction, and the system's geometric characteristics, as used in electrical bioimpedance spectroscopy (EBIS) [100]:

$$
\begin{aligned}
C_{\text {mem }}(\omega) & =\frac{9 \varphi R \varepsilon}{4 d} G, \\
R_{i}(\omega) & =\frac{4\left(\left(1 / 2 \sigma_{m}\right)+\left(1 / \sigma_{i}\right)\right)}{9 \varphi G} .
\end{aligned}
$$

\section{Modeling of Dielectric Attributes of Cells}

The dielectric traits of the variant components of a cell can be calculated with various approaches. Maxwell found that, to extract the resistivity of complex material, the resistivities of all small components should be counted together [104]. Later, this model was extended by Wagner [105], who demarcated the elements of such materials in terms of the complex conductivities. Some of them are mentioned below.

5.1. Permittivity of Cells in Dilute Suspensions. Consider a field $E$ applied to a fluidic medium (with permittivity $\varepsilon_{m}$ ) contains cells, each cell having $R_{c}$ radius and $R_{c}$ permittivity. In a spherical region (radius $R_{m}$ ) within the medium that contains $n$ number of cells, the potential at $r$ distance away from the center of the spherical region of cells is as follows [106]:

$$
\phi_{1}=\left(\frac{n A}{r^{2}}-B r\right) E \cos \theta,
$$

where

$$
A=\left(\frac{\varepsilon_{c}-\varepsilon_{m}}{\varepsilon_{c}+2 \varepsilon_{m}}\right) R_{c}^{3} .
$$

The volume $\left(v_{c}\right)$ fraction of suspended cells is

$$
v_{c}=\frac{n R_{c}^{3}}{R_{m}^{3}} .
$$

Inserting (45) and (46) into (44) yields

$$
\phi_{1}=\left(v_{c} R_{m}^{2} \frac{\varepsilon_{c}-\varepsilon_{m}}{\varepsilon_{c}+2 \varepsilon_{m}} \frac{1}{r^{2}}-B r\right) E \cos \theta .
$$

Now consider another similar sphere where the permittivity of the cells enclosed inside is homogeneous, with effective permittivity $\left(\varepsilon_{\text {eff }}\right)$. Thus, the new potential is as follows:

$$
\phi_{2}=\left(R_{m}^{3} \frac{\varepsilon_{\text {eff }}-\varepsilon_{m}}{\varepsilon_{\text {eff }}+2 \varepsilon_{m}} \frac{1}{r^{2}}-B r\right) E \cos \theta .
$$

If both spheres have the same dielectric properties, then

$$
\left(\frac{\varepsilon_{\mathrm{eff}}-\varepsilon_{m}}{\varepsilon_{\mathrm{eff}}+2 \varepsilon_{m}}\right)=v_{c}\left(\frac{\varepsilon_{c}-\varepsilon_{m}}{\varepsilon_{c}+2 \varepsilon_{m}}\right) .
$$

\subsection{Effective Medium Theory}

5.2.1. Mixture Equations by the Maxwell-Wagner Relation. 


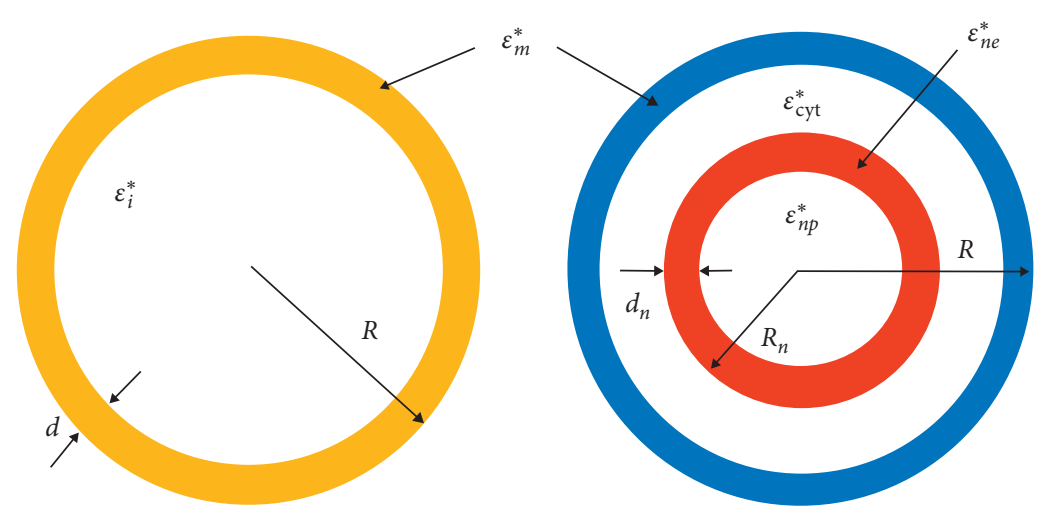

Figure 5: Illustration of (a) the one shell model and (b) dual shell model. All the subscripts for the complex permittivity designate the plasma membrane $(m)$, inner phase of the cell $(i)$, cytoplasm (cyt), nuclear envelope (ne), and nucleoplasm ( $n p)$. The other parameters are as follows: the outer cell radius $(R)$, outer radius of the nucleus $\left(R_{n}\right)$, plasma membrane thickness $(d)$, and thickness of the nuclear envelope $(d n)$.

Mixture equations describe the permittivity or conductivity of cells and other components in a medium. The measured permittivity value in a dielectric measurement of a cell mixture is $\varepsilon_{\text {eff. }}$ To study the conduction effects in terms of the complex permittivity, (52) replaces $\varepsilon_{\text {eff }}$ and $\varepsilon_{m}$ by $\varepsilon_{\text {eff }}^{*}$ and $\varepsilon_{m}^{*}$, respectively:

$$
\left(\frac{\varepsilon_{\mathrm{eff}}^{*}-\varepsilon_{m}^{*}}{\varepsilon_{\mathrm{eff}}^{*}+2 \varepsilon_{m}^{*}}\right)=v_{c}\left(\frac{\varepsilon_{c}^{*}-\varepsilon_{m}^{*}}{\varepsilon_{c}^{*}+2 \varepsilon_{m}^{*}}\right) .
$$

Upon rearranging (53), the effective complex permittivity of the fluid medium $\varepsilon_{m}^{*}$ in the spherical volume is given in terms of the complex permittivity of the suspended cells $\varepsilon_{c}^{*}$ :

$$
\varepsilon_{\mathrm{eff}}^{*}=\frac{2 \varepsilon_{m}^{*}+\varepsilon_{c}^{*}+2 \nu_{c}\left(\varepsilon_{c}^{*}-\varepsilon_{m}^{*}\right)}{2 \varepsilon_{m}^{*}+\varepsilon_{c}^{*}-\nu_{c}\left(\varepsilon_{c}^{*}-\varepsilon_{m}^{*}\right)} \varepsilon_{m}^{*} .
$$

The complex permittivity and conductivity can be expressed in terms of each other as follows [106]:

$$
\sigma^{*}=i \omega \varepsilon_{0} \varepsilon^{*}
$$

The above expression (55) leads to the same relation $\varepsilon_{\text {eff }}^{*}$ as that defined by Wagner [107]. Equation (54) describes the average permittivity of the cells in the suspension. If $\varepsilon_{\mathrm{eff}}^{*}$ and $\varepsilon_{m}^{*}$ are approximately equal, then heterogeneous and homogeneous materials are considered equal. Using this fact, in (54), following expression has been obtained:

$$
\varepsilon_{\mathrm{eff}}^{*}=\varepsilon_{m}^{*}\left(1+3 \nu_{c} \frac{\varepsilon_{c}^{*}-\varepsilon_{m}^{*}}{\varepsilon_{c}^{*}+2 \varepsilon_{m}^{*}}\right) .
$$

This equation is called the Maxwell-Wagner equation, which states that if the volume concentration $\left(v_{c}\right)$ of the biological cells rises from zero, then the suspension permittivity rises linearly with the rise in cell concentration. To obtain the effective mixture equations, segregate the real and imaginary terms of (56). The relationships between $\varepsilon_{\text {eff }}^{\prime}$ and $\sigma_{\text {eff }}^{\prime}$ appear as follows:

$$
\begin{gathered}
\varepsilon_{\mathrm{eff}}^{\prime}=\varepsilon_{\infty}^{\prime}+\frac{\varepsilon_{s}^{\prime}-\varepsilon_{\infty}^{\prime}}{1+i \omega \tau}, \\
\sigma_{\mathrm{eff}}^{\prime}=\sigma_{\infty}^{\prime}+\frac{\sigma_{s}^{\prime}-\sigma_{\infty}^{\prime}}{1+i \omega \tau},
\end{gathered}
$$

with

$$
\begin{gathered}
\tau=\varepsilon_{0} \frac{\varepsilon_{c}^{\prime}+2 \varepsilon_{m}^{\prime}}{\sigma_{c}^{\prime}+2 \sigma_{m}^{\prime}}, \\
\left(\varepsilon_{s}^{\prime}-\varepsilon_{\infty}^{\prime}\right)=\Delta \varepsilon_{\mathrm{eff}}^{\prime}=9 v_{c} \frac{\left(\varepsilon_{c}^{\prime} \sigma_{m}^{\prime}-\varepsilon_{m}^{\prime} \sigma_{m}^{\prime}\right)^{2}}{\left(\varepsilon_{c}^{\prime}+2 \varepsilon_{m}^{\prime}\right)\left(\sigma_{c}^{\prime}+2 \sigma_{m}^{\prime}\right)^{2}}, \\
\left(\sigma_{\infty}^{\prime}-\sigma_{s}^{\prime}\right)=\Delta \sigma_{\mathrm{eff}}^{\prime}=\frac{1}{\tau} \Delta \varepsilon_{\mathrm{eff}}^{\prime} .
\end{gathered}
$$

The foundation of the effective medium theory is the approximation that states that heterogeneous and homogeneous materials are considered equal for a large observation scale.

5.2.2. Mixture Equations by Hanai. Hanai [108] extended the Maxwell-Wagner equation for highly concentrated suspensions, which involve gradually increasing the volume fraction $v_{c}$ in increments $\Delta v_{c}$, which increases the mixture permittivity from $\varepsilon_{\text {mix }}^{*} \longrightarrow \varepsilon_{\text {mix }}^{*}+\Delta \varepsilon_{\text {mix }}^{*}$. The new volume fraction is $\Delta v_{c} /\left(1-\Delta v_{c}\right)$, while $\varepsilon_{m}^{*}$ changes to $\varepsilon_{\text {mix }}^{*}$. Inserting these substitutions into the Maxwell-Wagner equation, (56) yields

$$
\Delta \varepsilon_{\text {mix }}^{*} \simeq \frac{3 \varepsilon_{\text {mix }}^{*} \Delta \widehat{\nu}_{c}\left(\varepsilon_{c}^{*}-\varepsilon_{\text {mix }}^{*}\right)}{\left(1-\widehat{\nu}_{c}\right)\left(\varepsilon_{c}^{*}+2 \varepsilon_{\text {mix }}^{*}\right)} .
$$

Integrate the above equation with limits from 0 to $v_{c}$ and $\varepsilon_{m}^{*}$. to $\varepsilon_{\text {mix }}^{*}$. The following relationship arises

$$
\left(1-\bar{v}_{c}\right)=\frac{\left(\varepsilon_{\text {mix }}^{*}-\varepsilon_{c}^{*}\right)}{\left(\varepsilon_{m}^{*}-\varepsilon_{c}^{*}\right)}\left(\frac{\varepsilon_{m}^{*}}{\varepsilon_{\text {mix }}^{*}}\right)^{1 / 3} .
$$




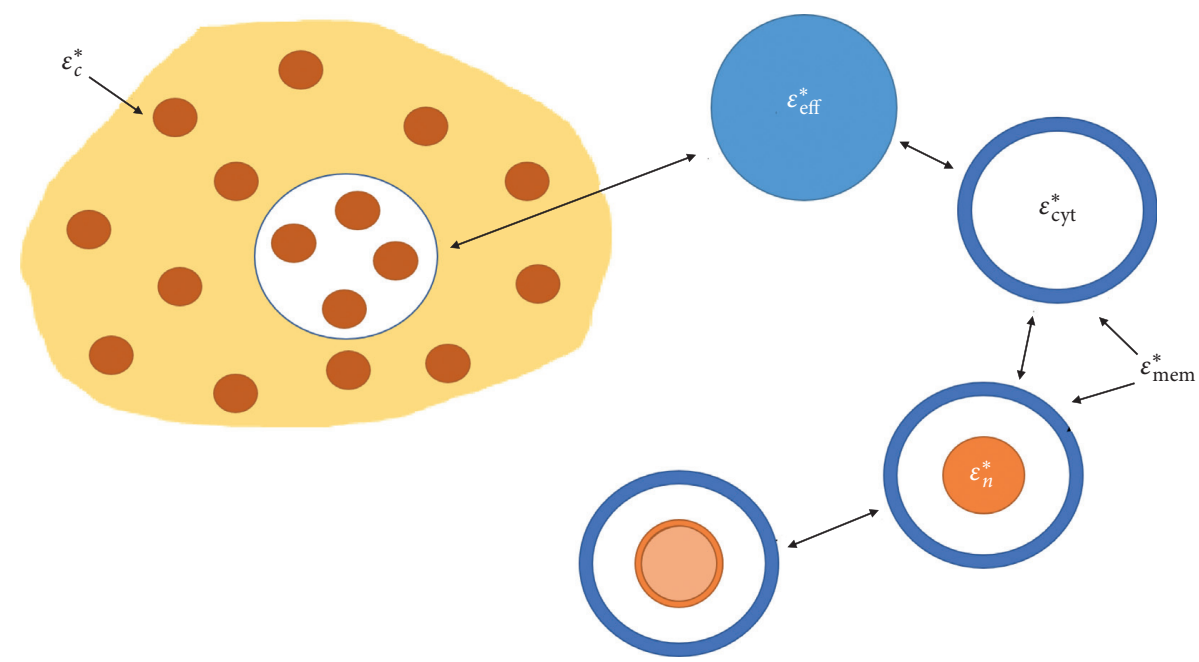

FIgURE 6: A schematic depicting how to derive the effective complex permittivity $\varepsilon_{\text {eff }}^{*}$ of a cell inside the suspension.

TABLE 5: Distinct electrical-based cancer cells detection techniques.

\begin{tabular}{|c|c|c|c|c|c|}
\hline & {$[111]$} & {$[112]$} & [113] & {$[5]$} & {$[114]$} \\
\hline Technique & $\begin{array}{l}\text { Phase-shifting laser } \\
\text { microscopy (PLM) }\end{array}$ & $\begin{array}{c}\text { Atomic force } \\
\text { microscopy (AFM) }\end{array}$ & $\begin{array}{c}\text { Gas chromatography } \\
\text { Mass spectrometry (GC- } \\
\text { MS) }\end{array}$ & $\begin{array}{l}\text { Capacitive-voltage } \\
\text { and capacitive- } \\
\text { frequency method }\end{array}$ & $\begin{array}{l}\text { Electrical impedance } \\
\text { spectroscopy (EIS) }\end{array}$ \\
\hline $\begin{array}{l}\text { Parameters } \\
\text { determined }\end{array}$ & $\begin{array}{l}\text { (i) Phase shifts } \\
\text { (ii) Cancer index }\end{array}$ & $\begin{array}{l}\text { (i) Young's modulus } \\
\text { (ii) Single cell elasticity }\end{array}$ & $\begin{array}{l}\text { At } 2 \text { different } \mathrm{pH} \text { values } \\
\text { (pH } 7 \text { and } \mathrm{pH} \text { 2): } \\
\text { (i) Volatile profiling } \\
\text { (ii) Metabolomic } \\
\text { profiling } \\
\text { (iii) Effect size } \\
\text { (iv) Percentage of } \\
\text { variation }\end{array}$ & $\begin{array}{l}\text { (i) Polarization } \\
\text { (ii) Dielectric } \\
\text { properties }\end{array}$ & $\begin{array}{l}\text { Resistance and } \\
\text { capacitance at } 4 \\
\text { phases: } \\
\text { (i) Growth } \\
\text { (ii) Confluence } \\
\text { (iii) Wounding } \\
\text { (iv) Healing }\end{array}$ \\
\hline Analysis & $\begin{array}{l}\text { Bird's eye view of } \\
\text { phase-shift analysis }\end{array}$ & Hertz-Sneddon model & $\begin{array}{c}\text { Statistical analysis: PCA } \\
\text { and PLS-DA }\end{array}$ & Capacitive modelling & $\begin{array}{l}\text { Feature analysis and } \\
\text { selection with linear } \\
\text { discriminant analysis }\end{array}$ \\
\hline Pros & $\begin{array}{l}\text { (i) Less time } \\
\text { consumption } \\
\text { (ii) NN are flexible and } \\
\text { used for both } \\
\text { regression and } \\
\text { classification problems } \\
\text { (iii) Can model with } \\
\text { nonlinear data with } \\
\text { large number of inputs } \\
\text { (iv) Once prepared, the } \\
\text { predictions are fast }\end{array}$ & $\begin{array}{l}\text { (i) Resolution: } \\
-0.5-5 \mathrm{~nm} \text { depth and } \\
-0.2-10.0 \mathrm{~nm} \text { (lateral) } \\
\text { (ii) For conductive } \\
\text { and nonconductive } \\
\text { (iii) Can be used for } \\
\text { nanocrystals and } \\
\text { nanotubes as well }\end{array}$ & $\begin{array}{l}\text { (i) Suitable for certain } \\
\text { analytes } \\
\text { (ii) Many well- } \\
\text { established protocols } \\
\text { (iii) Faster method } \\
\text { development }\end{array}$ & $\begin{array}{c}\text { (i) Fast } \\
\text { (ii) Sensitive } \\
\text { (iii) No } \\
\text { preprocessing steps }\end{array}$ & $\begin{array}{l}\text { (i) Consistent results } \\
\text { (ii) Nondestructive } \\
\text { techniques, hence less } \\
\text { material is required } \\
\text { (iii) Cell sorting } \\
\text { (iv) High resolution }\end{array}$ \\
\hline Cons & $\begin{array}{l}\text { (i) Histograms of } \\
\text { different cells are } \\
\text { overlapping; hence, } \\
\text { sensitivity and } \\
\text { specificity needs to } \\
\text { improve } \\
\text { (ii) The tableland and } \\
\text { cone shapes are } \\
\text { considered as the } \\
\text { distinctive shape of } \\
\text { normal and cancer } \\
\text { cells, which is not a } \\
\text { promising feature }\end{array}$ & $\begin{array}{l}\text { (i) Its clinical use } \\
\text { needs more systematic } \\
\text { studies } \\
\text { (ii) Structural } \\
\text { complexity and } \\
\text { heterogeneity of } \\
\text { tumor questions the } \\
\text { relevance of elasticity } \\
\text { measurements }\end{array}$ & $\begin{array}{l}\text { (i) The integration of } \\
\text { volatile organic } \\
\text { compounds (VOCs) in } \\
\text { specific metabolic } \\
\text { pathways is still very } \\
\text { difficult and needs more } \\
\text { studies }\end{array}$ & $\begin{array}{l}\text { (i) Capacitive values } \\
\text { may vary from one } \\
\text { investigational setup } \\
\text { to another } \\
\text { (ii) Single cell } \\
\text { analysis is required } \\
\text { to produce more } \\
\text { precise results for the } \\
\text { intrinsic properties } \\
\text { of cells }\end{array}$ & $\begin{array}{l}\text { (i) To determine cancer } \\
\text { cells in coculture inside } \\
\text { a single well containing } \\
\text { a set of spatially } \\
\text { distributed } \\
\text { microelectrodes }\end{array}$ \\
\hline
\end{tabular}


TABLE 5: Continued.

\begin{tabular}{|c|c|c|c|c|c|}
\hline & [111] & [112] & {$[113]$} & {$[5]$} & [114] \\
\hline $\begin{array}{l}\text { Processing } \\
\text { time }\end{array}$ & Few hours & Few hours to one day & $\begin{array}{c}\text { Few days: as VOCs take } \\
\text { at least } 2 \text { days }\end{array}$ & Few minutes & Few days \\
\hline Reliability & Less reliable & $\begin{array}{l}\text { Less reliable due to the } \\
\text { following: } \\
\text { (i) Small scan image } \\
\text { size and restricted } \\
\text { speed } \\
\text { (ii) Slow rate of } \\
\text { scanning leads to } \\
\text { thermal drift } \\
\text { (iii) Images affected by } \\
\text { hysteresis property of } \\
\text { the piezoelectric } \\
\text { material }\end{array}$ & $\begin{array}{l}\text { Moderate reliable: as it } \\
\text { does not produce } \\
\text { accurate results for all cell } \\
\text { lines }\end{array}$ & Yes & Yes \\
\hline Errors & $\begin{array}{c}\text { Error in case of } \\
\text { contamination only }\end{array}$ & - & $\begin{array}{l}\text { Separate errors for each } \\
\text { sample }\end{array}$ & Error of $5 \%$ & Error of $4.5 \%$ \\
\hline
\end{tabular}

TABLE 6: Single-cell analysis by microfluidic techniques.

\begin{tabular}{lccc}
\hline Approaches technique & Pros & Cons & Applications \\
\hline $\begin{array}{l}\text { Electrorotation } \\
\text { Impedance flow cytometry }\end{array}$ & $\begin{array}{c}\text { Quantify intrinsic electrical properties of } \\
\text { cells }\end{array}$ & $\begin{array}{c}\text { (i) Low throughput } \\
\text { (ii) Low } \\
\text { conductivity }\end{array}$ & Monitor parasite and cell separation \\
\hline $\begin{array}{l}\text { Microelectrical impedance } \\
\text { spectroscopy }\end{array}$ & High throughput & Low specificity & $\begin{array}{c}\text { Cell sorting, cell counting, cell } \\
\text { impedance }\end{array}$ \\
\hline
\end{tabular}

This is called the Hanai mixture equation, and this relationship is typically used to analyze dielectric measurements performed with cell suspensions.

5.3. Modeling of a Cell. Cell modeling can be performed on two bases: the single-shell model of the cell and the dualshell model of the cell, where shells are represented by the quantity of membranes. The bilayer-membrane structure of the nuclear envelope involves one homogeneous shell, while the dual membrane requires a triple-shell model. Figure 5 shows both types of cell structure modeling.

A sphere of radius $R_{1}$ is situated concentrically within a larger sphere of radius $R_{2}$. The basic model of the spherical cell does not contain a nucleus or internal organelles. The volume fraction is given by $v_{c}=\left(R_{1} / R_{2}\right)^{3}$, and the following relationship is derived:

$$
\varepsilon_{\text {cell }}^{*}=\frac{\left(2 \varepsilon_{\mathrm{mem}}^{*}+\varepsilon_{\mathrm{cyt}}^{*}\right) R_{2}^{3}+2\left(\varepsilon_{\mathrm{cyt}}^{*}-\varepsilon_{\mathrm{mem}}^{*}\right) R_{1}^{3}}{\left(2 \varepsilon_{\mathrm{mem}}^{*}+\varepsilon_{\mathrm{cyt}}^{*}\right) R_{2}^{3}-\left(\varepsilon_{\mathrm{cyt}}^{*}-\varepsilon_{\mathrm{mem}}^{*}\right) R_{1}^{3}} \varepsilon_{\mathrm{mem}}^{*},
$$

where $R_{2}$ and $d$ are the cell radius and the membrane thickness, respectively, where $d=R_{2}-R_{1}$.

It is inferred that the one-shell model has limitations for describing the dielectric properties of the cells completely, as cells contain many organelles along with membranes [109]. The single-shell model considers only the plasma membrane for a cell without including the nucleus, whereas the dual- shell model includes a nuclear envelope which has been treated as a separate homogeneous membrane ([109], p. 51) [110]. Figure 6 schematizes the extraction of the effective complex permittivity via (54) and (61).

\section{Perspective}

Available technologies keep growing and getting mature for every biological entity, even for single-cell and its mixtures. Their parameters, the number of cells, and molecules detected will certainly surge over time. This results in the growing demand to integrate single-cell data in experiments by using their properties on an individual level. Ultimately, single-cell analysis (SCA) helps in detecting the type of ailments related to it and will create a better single-cell view. Moreover, it reveals the fundamental basis for cellular functions and deduces underlying associations between variant modalities.

Some cell sample mixtures include cancerous cells, neurons, immune cells, stem cells, and many other types which makes it a heterogeneous sample having stochastic nature. However, few hundreds of cells, in some cases, can provide a good depiction of the original cell population. However, the conventional procedures based on the average of a population with this number of cells usually are not effective, particularly in heterogeneous cell pools. Some of them are compared in Table 5.

When a large number of samples are analyzed, SCA helps us to classify the types of cells, in their normal 
physiological and pathologic states. Various technologies and methods mentioned here will further enhance and expand allowing SCA applications to contribute to the quality of human life along with other species, and a few of them are depicted in Table 6. It has a huge scope in the future and will unquestionably make exclusive and powerful contributions to medical sciences and engineering.

6.1. Why Microfluidic Devices are More Efficient than Conventional Cell Culture Techniques? These can imitate the microenvironments of cells and their influence on organ functions that help to explore disease models. Hence, the whole biological process gets integrated and simplified for the end-users. It provides faster analyses, point-of-care applications, good throughput, low material consumptions, high accuracy, faster heat dissipation, reduced complexity, and in situ observation of cell response. This technology initiates a new standard in cellular and microbiology research for early illness detection and offers critical knowledge required by researchers for improved clinical diagnosis and patient outcome.

\section{Conclusion}

Single-cell analysis not only detects the abnormal cells but also helps in the identification of the type of the cell. This study deals with the various electrical properties related to biological cells. Some of the electrical properties have been discussed, such as the dielectric dispersions, which include the $\alpha$-, $\beta$-, $\gamma^{-}$, and $\delta$-dispersions; polarization and its types, such as electronic, atomic, and orientation polarization; and relaxation with related theories and modeling of the static and dynamic permittivity. Maxwell's mixture theory has been explained along with the modeling of the dielectric properties of cells. The modeling of cells includes the permittivity of dilute suspensions of cells and the effective medium theory of Maxwell and Hanai. Moreover, comparison of various available electrical techniques have been discussed, especially for single cell or group of cells. Furthermore, importance of microfluidics with other new SCA devices have been discussed. This study about methodologies and available cell modeling is useful for researchers working in this field and may help in creating a better comparison of the conventional and current theories, together.

\section{Nomenclature}

$\begin{array}{ll}\alpha_{0}: & \text { Polarizability } \\ \alpha, \beta, \gamma, \delta: & \text { Dispersions } \\ \varepsilon: & \text { Permittivity } \\ \Delta \varepsilon: & \text { Dielectric decrements } \\ \delta: & \text { Surface charge density } \\ \sigma: & \text { Conductivity } \\ \varphi: & \text { Volume fraction } \\ \omega: & \text { Angular frequency } \\ \tau: & \text { Relaxation time } \\ \mu: & \text { Dipole moment } \\ A: & \text { Area of electrodes } \\ C: & \text { Capacitance }\end{array}$

$\begin{array}{ll}d: & \text { Density } \\ D: & \text { Dielectric displacement } \\ E: & \text { Electric field } \\ \dot{f}_{\mathrm{CM}}: & \text { Clausius-Mossotti factor } \\ F: & \text { Force } \\ g: & \text { Correlation parameter or gap between electrodes } \\ G: & \text { Geometric constant } \\ K: & \text { Boltzmann constant } \\ L: & \text { Inductance } \\ N: & \text { Number of molecules per mole or number of } \\ & \text { dipoles } \\ m: & \text { Electric moment } \\ M: & \text { Molecular weight } \\ M^{\prime}: & \text { Momentum } \\ p: & \text { Molar polarization } \\ P: & \text { Polarization } \\ r \text { or } R: & \text { Resistance or radius } \\ v \text { or } V: & \text { Volume } \\ T: & \text { Temperature } \\ Z: & \text { Impedance. }\end{array}$

\section{Conflicts of Interest}

The authors declare that they have no conflicts of interest.

\section{Acknowledgments}

This work was supported in part by the College of Engineering, under Grant 31R085.

\section{References}

[1] Y. Liu, Y. Guo, Y. Guo et al., "Characteristics extraction and analysis on the electrical signals of spinal dorsal root nerve evoked by acupuncture manipulations," in Proceedings of the 2011 4th International Conference on Biomedical Engineering and Informatics (BMEI), vol. 2, pp. 680-684, Shanghai, China, October 2011.

[2] M. B. I. Raez, M. S. Hussain, and F. Mohd-Yasin, "Techniques of EMG signal analysis: detection, processing, classification and applications," Biological Procedures Online, vol. 8, no. 1, pp. 11-35, 2006.

[3] U. Kunzmann, G. Wagner, J. Schöchlin, and A. Bolz, "Parameter extraction of ecg signals in real-time," Biomedizinische Technik/Biomedical Engineering, vol. 47, no. s1b, pp. 875-878, 2002.

[4] J. A. Alqabandi, U. M. Abdel-Motal, and K. Youcef-Toumi, "Extracting cancer cell line electrochemical parameters at the single cell level using a microfabricated device," Biotechnology Journal, vol. 4, no. 2, pp. 216-223, 2009.

[5] M. A. Ahmad, Z. A. Natour, F. Mustafa, and T. A. Rizvi, "Electrical characterization of normal and cancer cells," IEEE Access, vol. 6, pp. 25979-25986, 2018.

[6] M. A. Ahmad, F. Mustafa, L. M. Ali, and T. A. Rizvi, "Virus detection and quantification using electrical parameters," Scientific Reports, vol. 4, no. 1, 2014.

[7] M. A. Ahmad, N. G. Panicker, T. A. Rizvi, and F. Mustafa, "Electrical detection and quantification of single and mixed DNA nucleotides in suspension," Scientific Reports, vol. 6, no. 1, 2016. 
[8] M. A. Ahmad, "Electrical detection, identification, and quantification of exosomes," IEEE Access, vol. 6, pp. 22817-22826, 2018.

[9] A. Fontes, M. L. B. Castro, A. Fontes et al., "Mechanical and electrical properties of red blood cells using optical tweezers," Journal of Optics, vol. 13, no. 4, Article ID 044012, 2011.

[10] G. Qiao, W. Duan, C. Chatwin, A. Sinclair, and W. Wang, "Electrical properties of breast cancer cells from impedance measurement of cell suspensions," Journal of Physics: Conference Series, vol. 224, Article ID 012081, 2010.

[11] J.-H. Lee, B.-C. Kim, B.-K. Oh, and J.-W. Choi, "Highly sensitive electrical detection of HIV-1 virus based on scanning tunneling microscopy," Journal of Nanoscience and Nanotechnology, vol. 15, no. 2, pp. 1117-1122, 2015.

[12] J.-H. Lee, B.-K. Oh, and J.-W. Choi, "Development of a HIV1 virus detection system based on Nanotechnology," Sensors, vol. 15, no. 5, pp. 9915-9927, 2015.

[13] S. H. Kim, Y. J. Park, J. Woo, and B. Y. Majlis, "Highly selective dengue virus detection using carbon nanotubes: effect of pulse biasing in serum," in Proceedings of the 2015 IEEE 15th International Conference on Nanotechnology (IEEE-NANO), pp. 1066-1069, Rome, Italy, July 2015.

[14] D. Wasik, A. Mulchandani, and M. V. Yates, "A heparinfunctionalized carbon nanotube-based affinity biosensor for dengue virus," Biosensors and Bioelectronics, vol. 91, pp. 811-816, 2017.

[15] D. M. Elsheikh, H. A. Elsadek, E. A. Abdallah, S. Atteya, and W. N. ELmazny, "Rapid detection of blood entero-viruses using microstrip antenna bio-sensor," in Proceedings of the 2013 European Microwave Conference, pp. 878-880, Nuremberg, Germany, October 2013.

[16] M. Nakano, Z. Ding, and J. Suehiro, "Dielectrophoresis and dielectrophoretic impedance detection of adenovirus and rotavirus," Japanese Journal of Applied Physics, vol. 55, no. 1, Article ID 017001, 2015.

[17] M. Nakano, R. Obara, Z. Ding, and J. Suehiro, "Detection of norovirus and rotavirus by dielectrophoretic impedance measurement," in Proceedings of the 2013 Seventh International Conference on Sensing Technology (ICST), pp. 374-378, Wellington, New Zealand, December 2013.

[18] M. Ouyang, W. J. Li, K. W. Wong, and W. K. Liu, "Investigation of electrical properties of DNA-attached carbon nano-particles for biological applications," in Proceedings of the 2012 7th IEEE International Conference on Nano/Micro Engineered and Molecular Systems (NEMS), pp. 429-432, Kyoto, Japan, March 2012.

[19] H. An, Q. Liu, Q. Ji, and B. Jin, "DNA binding and aggregation by carbon nanoparticles," Biochemical and Biophysical Research Communications, vol. 393, no. 4, pp. 571-576, 2010.

[20] A. Yan, B. W. Lau, B. S. Weissman et al., "Biocompatible, hydrophilic, supramolecular carbon nanoparticles for cell delivery," Advanced Materials, vol. 18, no. 18, pp. 2373-2378, 2006.

[21] P. Chopade, S. H. Moh, V. Kanade, T. Kim, A. Kulkarni, and S. H. Park, "Distinct characteristics of DNA field effect transistors embedded with marine-derived porphyra-334 under UV illumination," AIP Advances, vol. 9, no. 2, Article ID 025212, 2019.

[22] S. Maeno, S. Takagi, N. Matsuo et al., "Electrical property of DNA field-effect transistor; Charge retention property," in Proceedings of the 2012 IEEE International Meeting for Future of Electron Devices, pp. 1-2, Kansai, Japan, June 2012.
[23] N. Arshad and S. I. Farooqi, "Cyclic voltammetric DNA binding investigations on some anticancer potential metal complexes: a review," Applied Biochemistry and Biotechnology, vol. 186, no. 4, pp. 1090-1110, 2018.

[24] D. Jiang, G. Xiang, C. Liu, J. Yu, L. Liu, and X. Pu, "Development of a cyclic voltammetry method for DNA electrochemical detection on microfluidic gene chip," International Journal of Electrochemical Science, vol. 7, no. 13, 2012.

[25] C. H. Wohlgamuth, M. A. McWilliams, and J. D. Slinker, "DNA as a molecular wire: distance and sequence dependence," 2019, https://pubs.acs.org/doi/full/10.1021/ac401229q.

[26] C. M. Bui, Temperature effect on DNA molecular wires, $\mathrm{PhD}$ thesis, 2016.

[27] D. Mandal, S. Khatun, A. N. Gupta, and A. Chandra, "DNA supported graphene quantum dots for Ag ion sensing," Nanotechnology, vol. 30, no. 25, Article ID 255501, 2019.

[28] S. Rafiei, M. Dadmehr, M. Hosseini, H. A. Kermani, and M. R. Ganjali, "A fluorometric study on the effect of DNA methylation on DNA interaction with graphene quantum dots," Methods and Applications in Fluorescence, vol. 7, no. 2, Article ID 025001, 2019.

[29] A. Henning, F. F. Bier, and R. Hölzel, "Dielectrophoresis of DNA: Quantification by impedance measurements," Biomicrofluidics, vol. 4, no. 2, Article ID 022803, 2010.

[30] M. Viefhues and R. Eichhorn, "DNA dielectrophoresis: theory and applications a review," Electrophoresis, vol. 38, no. 11, pp. 1483-1506, 2017.

[31] H. M. Coley, F. H. Labeed, H. Thomas, and M. P. Hughes, "Biophysical characterization of MDR breast cancer cell lines reveals the cytoplasm is critical in determining drug sensitivity," Biochimica et Biophysica Acta (BBA)_General Subjects, vol. 1770, no. 4, pp. 601-608, 2007.

[32] Y. Cho, H. S. Kim, A. B. Frazier, Z. G. Chen, D. M. Shin, and A. Han, "Whole-cell impedance analysis for highly and poorly metastatic cancer cells," Journal of Microelectromechanical Systems, vol. 18, no. 4, pp. 808-817, 2009.

[33] Y. Zhao, D. Chen, Y. Luo et al., "A microfluidic system for cell type classification based on cellular size-independent electrical properties," Lab on a Chip, vol. 13, no. 12, pp. 2272-2277, 2013.

[34] S. Byun, S. Son, D. Amodei et al., "Characterizing deformability and surface friction of cancer cells," Proceedings of the National Academy of Sciences, vol. 110, no. 19, pp. 75807585, 2013.

[35] Y. Zhao, X. T. Zhao, D. Y. Chen et al., "Tumor cell characterization and classification based on cellular specific membrane capacitance and cytoplasm conductivity," Biosensors and Bioelectronics, vol. 57, pp. 245-253, 2014.

[36] M. R. Nurliyana, M. Z. Sahdan, K. M. Wibowo et al., "The detection method of Escherichia coli in water resources: a review," Journal of Physics: Conference Series, vol. 995, Article ID 12065, 2018.

[37] K. Settu, C.-J. Chen, J.-T. Liu, C.-L. Chen, and J.-Z. Tsai, "Impedimetric method for measuring ultra-low E. coli concentrations in human urine," Biosensors and Bioelectronics, vol. 66, pp. 244-250, 2015.

[38] K. Settu, C.-J. Chen, J.-T. Liu, and J.-Z. Tsai, "Capacitance sensor for detecting Escherichia Coli in urinary tract infection diagnosis," Journal of Microbiology, Immunology and Infection, vol. 48, no. 2, p. S81, 2015.

[39] W. Roobsoong, S. P. Maher, N. Rachaphaew et al., "A rapid sensitive, flow cytometry-based method for the detection of 
Plasmodium vivax-infected blood cells," Malaria Journal, vol. 13, no. 1, p. 55, 2014.

[40] B. Malleret, C. Claser, A. S. M. Ong et al., "A rapid and robust tri-color flow cytometry assay for monitoring malaria parasite development," Scientific Reports, vol. 1, p. 118, 2011.

[41] F. Asphahani and M. Zhang, "Cellular impedance biosensors for drug screening and toxin detection," The Analyst, vol. 132, no. 9, pp. 835-841, 2007.

[42] K. E. Moeller, J. C. Kissack, R. S. Atayee, and K. C. Lee, "Clinical interpretation of urine drug tests," Mayo Clinic Proceedings, vol. 92, no. 5, pp. 774-796, 2017.

[43] S.-I. Han, Y.-D. Joo, and K.-H. Han, "An electrorotation technique for measuring the dielectric properties of cells with simultaneous use of negative quadrupolar dielectrophoresis and electrorotation," The Analyst, vol. 138, no. 5, pp. 1529-1537, 2013.

[44] D. A. Dean, D. Machado-Aranda, T. Ramanathan, I. Molina, and R. Sundararajan, "Electrical Properties of Biological Tissues - an Impedance Spectroscopy Study," in Proceedings of the 2006 IEEE Conference on Electrical Insulation and Dielectric Phenomena, pp. 357-360, Kansas, MO, USA, October, 2006.

[45] S. Gabriel, R. W. Lau, and C. Gabriel, "The dielectric properties of biological tissues: III. Parametric models for the dielectric spectrum of tissues," Physics in Medicine and Biology, vol. 41, no. 11, pp. 2271-2293, 1996.

[46] M. A. Mansor and M. R. Ahmad, "Single cell electrical characterization techniques," International Journal of Molecular Sciences, vol. 16, no. 12, pp. 12686-12712, 2015.

[47] "Radiography (plain X-rays): understanding medical radiation," 2019, https://www.medicalradiation.com/types-ofmedical-imaging/imaging-using-x-rays/radiography-plain$\mathrm{x}$-rays/.

[48] "Magnetic resonance imaging (MRI), part 1: how it works: analog IC tips," 2019, https://www.analogictips.com/ magnetic-resonance-imaging-part-1-how-it-works-faq/.

[49] H. D. Cheng, J. Shan, W. Ju, Y. Guo, and L. Zhang, "Automated breast cancer detection and classification using ultrasound images: a survey," Pattern Recognition, vol. 43, no. 1, pp. 299-317, 2010.

[50] P. B. Gordon, "Ultrasound for breast cancer screening and staging," Radiologic Clinics of North America, vol. 40, no. 3, pp. 431-441, 2002.

[51] F. M. Bengel, T. Higuchi, M. S. Javadi, and R. Lautamäki, "Cardiac Positron emission tomography," Journal of the American College of Cardiology, vol. 54, no. 1, pp. 1-15, 2009.

[52] M. Z. Mahmud, M. T. Islam, N. Misran, A. F. Almutairi, and M. Cho, "Ultra-wideband (UWB) antenna sensor based microwave breast imaging: a review," Sensors, vol. 18, no. 9, p. 2951, 2018.

[53] F. Lang and C. Stournaras, "Ion channels in cancer: future perspectives and clinical potential," Philosophical Transactions of the Royal Society B: Biological Sciences, vol. 369, 1638 pages, 2014.

[54] K. R. Foster, J. M. Bidinger, and D. O. Carpenter, "The electrical resistivity of cytoplasm," Biophysical Journal, vol. 16, no. 9, pp. 991-1001, 1976.

[55] S.-B. Huang, Y. Zhao, D. Chen et al., "A clogging-free microfluidic platform with an incorporated pneumatically driven membrane-based active valve enabling specific membrane capacitance and cytoplasm conductivity characterization of single cells," Sensors and Actuators B: Chemical, vol. 190, pp. 928-936, 2014.

[56] K. Wang, Y. Zhao, D. Chen et al., "Specific membrane capacitance, cytoplasm conductivity and instantaneous
Young's modulus of single tumour cells," Scientific Data, vol. 4, Article ID 170015, 2017.

[57] L.-S. Jang and M.-H. Wang, "Microfluidic device for cell capture and impedance measurement," Biomedical Microdevices, vol. 9, no. 5, pp. 737-743, 2007.

[58] M. Abdolahad, Z. Sanaee, M. Janmaleki, S. Mohajerzadeh, M. Abdollahi, and M. Mehran, "Vertically aligned multiwallcarbon nanotubes to preferentially entrap highly metastatic cancerous cells," Carbon, vol. 50, no. 5, pp. 2010-2017, 2012.

[59] Y. Katsumoto, K. Tatsumi, T. Doi, and K. Nakabe, "Electrical classification of single red blood cell deformability in highshear microchannel flows," International Journal of Heat and Fluid Flow, vol. 31, no. 6, pp. 985-995, 2010.

[60] A. M. Dondorp, P. A. Kager, J. Vreeken, and N. J. White, "Abnormal blood flow and red blood cell deformability in severe malaria," Parasitology Today, vol. 16, no. 6, pp. 228-232, 2000.

[61] J. Voldman, "Electrical forces for microscale cell manipulation," Annual Review of Biomedical Engineering, vol. 8, no. 1, pp. 425-454, 2006.

[62] G. E. Wnek and G. L. Bowlin, Encyclopedia of Biomaterials and Biomedical Engineering, CRC Press, Boca Raton, FL, USA, 2008.

[63] D. G. Grier, "A revolution in optical manipulation," Nature, vol. 424, no. 6950, pp. 810-816, 2003.

[64] A. L. Birkbeck, R. A. Flynn, M. Ozkan, D. Song, M. Gross, and S. C. Esener, "VCSEL arrays as micromanipulators in chip-based biosystems," Biomedical Microdevices, vol. 5, no. 1, pp. 47-54, 2003.

[65] D. J. Odde and M. J. Renn, "Laser-guided direct writing of living cells," Biotechnology and Bioengineering, vol. 67, no. 3, pp. 312-318, 2000.

[66] D. J. Odde and M. J. Renn, "Laser-guided direct writing for applications in biotechnology," Trends in Biotechnology, vol. 17, no. 10, pp. 385-389, 1999.

[67] D. Bazou, G. P. Dowthwaite, I. M. Khan, C. W. Archer, J. R. Ralphs, and W. Terence Coakley, "Gap junctional intercellular communication and cytoskeletal organization in chondrocytes in suspension in an ultrasound trap," Molecular Membrane Biology, vol. 23, no. 2, pp. 195-205, 2006.

[68] D. Bazou, L. A. Kuznetsova, and W. T. Coakley, "Physical enviroment of 2-D animal cell aggregates formed in a short pathlength ultrasound standing wave trap," Ultrasound in Medicine \& Biology, vol. 31, no. 3, pp. 423-430, 2005.

[69] M. Tanase, E. J. Felton, D. S. Gray, A. Hultgren, C. S. Chen, and D. H. Reich, "Assembly of multicellular constructs and microarrays of cells using magnetic nanowires," Lab on a Chip, vol. 5, no. 6, pp. 598-605, 2005.

[70] K. Ino, A. Ito, and H. Honda, "Cell patterning using magnetite nanoparticles and magnetic force," Biotechnology and Bioengineering, vol. 97, no. 5, pp. 1309-1317, 2007.

[71] P. Linkov, M. Artemyev, A. E. Efimov, and I. Nabiev, "Comparative advantages and limitations of the basic metrology methods applied to the characterization of nanomaterials," Nanoscale, vol. 5, no. 19, pp. 8781-8798, 2013.

[72] C. Henry, "XII. An account of some attempts to imitate the effects of the torpedo by electricity," Philosophical Transactions of the Royal Society A, vol. 66, pp. 196-225, 1776.

[73] Georg Simon Ohm (five papers, 1825-1853), JF Ptak Science Books, Blog Bookstore, May 2019, https://longstreet.typepad. com/books/2017/08/georg-simon-ohm-five-papers-1825-1853. html.

[74] J. Bernstein and A. Tschermak, "Untersuchungen zur Thermodynamik der bioelektrischen Ströme," Pflüger, 
Archiv für die Gesammte Physiologie des Menschen und der Thiere, vol. 112, no. 9-10, pp. 439-521, 1906.

[75] R. Höber, "Eine Methode, die elektrische Leitfähigkeit im Innern von Zellen zu messen," Pflüger's Archiv für die Gesammte Physiologie des Menschen und der Tiere, vol. 133, no. 4-6, pp. 237-253, 1910.

[76] R. Höber, "Messungen der inneren Leitfähigkeit von Zellen," Pflüger's Archiv für die Gesamte Physiologie des Menschen und der Tiere, vol. 150, no. 1-2, pp. 15-45, 1913.

[77] V. Raicu and Y. Feldman, Dielectric Relaxation in Biological Systems: Physical Principles, Methods, and Applications, OUP, Oxford, UK, 2015.

[78] H. Fricke and S. Morse, "The electric resistance and capacity OF blood for frequencies between 800 and 4 1/2 million cycles," The Journal of General Physiology, vol. 9, no. 2, pp. 153-167, Nov. 1925.

[79] K. S. Cole and R. F. Baker, "Longitudinal impedance OF the squid giant axon," The Journal of General Physiology, vol. 24, no. 6, pp. 771-788, 1941.

[80] R. Pethig and D. B. Kell, "The passive electrical properties of biological systems: their significance in physiology, biophysics and biotechnology," Physics in Medicine and Biology, vol. 32, no. 8, pp. 933-970, 1987.

[81] H. P. Schwan, "Electrical properties of tissue and cell suspensions," Advances in Biological and Medical Physics, vol. 5, pp. 147-209, 1957.

[82] G. H. Markx and C. L. Davey, "The dielectric properties of biological cells at radiofrequencies: applications in biotechnology," Enzyme and Microbial Technology, vol. 25, no. 3-5, pp. 161-171, 1999.

[83] Kramers-Kronig relations, Wikipedia, 2019.

[84] K. R. Waters, M. S. Hughes, J. Mobley, and J. G. Miller, "Differential forms of the Kramers-Kronig dispersion relations," IEEE Transactions on Ultrasonics, Ferroelectrics and Frequency Control, vol. 50, no. 1, pp. 68-76, 2003.

[85] J. S. Toll, "Causality and the dispersion relation: logical foundations," Physical Review, vol. 104, no. 6, pp. 1760-1770, 1956.

[86] J. P. Grant, "Measurements, medical significance and applications of the dielectric properties of biological materials," Doctoral thesis, University of Surrey, Guildford, UK, 1984.

[87] R. R. Pethig, Dielectrophoresis: Theory, Methodology and Biological Applications, John Wiley \& Sons, Hoboken, NJ, USA, 2017.

[88] K. Asami, "Characterization of biological cells by dielectric spectroscopy," Journal of Non-crystalline Solids, vol. 305, no. 1-3, pp. 268-277, 2002.

[89] M. Gotz, L. Karsch, and J. Pawelke, "A new model for volume recombination in plane-parallel chambers in pulsed fields of high dose-per-pulse," Physics in Medicine \& Biology, vol. 62, no. 22, pp. 8634-8654, 2017.

[90] K. R. Foster and H. P. Schwan, "Dielectric properties of tissues and biological materials: a critical review," Critical Reviews in Biomedical Engineering, vol. 17, no. 1, pp. 25-104, 1989.

[91] M.-R. Tofighi, "Chapter 2-interaction between electromagnetic waves and biological materials," in Principles and Applications of RF/Microwave in Healthcare and Biosensing, C. Li, M.-R. Tofighi, D. Schreurs, and T.-S. J. Horng, Eds., pp. 53-101, Academic Press, Cambridge, MA, USA, 2017.

[92] S. Riniker, A.-P. E. Kunz, and W. F. van Gunsteren, "On the calculation of the dielectric permittivity and relaxation of molecular models in the liquid phase," Journal of
Chemical Theory and Computation, vol. 7, no. 5, pp. 1469-1475, 2011.

[93] E. Talebian and M. Talebian, "A general review on the derivation of Clausius-Mossotti relation," Optik, vol. 124, no. 16, pp. 2324-2326, 2013.

[94] N. E. Hill, Dielectric Properties and Molecular Behaviour, Van Nostrand Reinhold, London, UK, 1969.

[95] Shodhganga, "Theories of Dielectric and Thermodynamic Parameters," INFLIBNET Centre, Gujarat, India, 2020, https:// shodhganga.inflibnet.ac.in/bitstream/10603/8332/13/13_chapter \%202.pdf.

[96] K. S. Cole and R. H. Cole, "Dispersion and absorption in dielectrics I. Alternating current characteristics," The Journal of Chemical Physics, vol. 9, no. 4, pp. 341-351, 1941.

[97] N. Bücher, "Polar molecules. By P. Debye, Ph.D., Pp. 172. New York: Chemical Catalog Co., Inc., 1929. \$ 3.50," Journal of the Society of Chemical Industry, vol. 48, no. 43, pp. 1036-1037, 1929.

[98] L. Gun, D. Ning, and Z. Liang, "Effective permittivity of biological tissue: comparison of theoretical model and experiment," Mathematical Problems in Engineering, vol. 2017, Article ID 7249672, 7 pages, 2017.

[99] P. Debye, Polar Molecules/by P. Debye, Chemical Catalog, New York, NY, USA, 1929.

[100] T. Sun and H. Morgan, "Single-cell microfluidic impedance cytometry: a review," Microfluidics and Nanofluidics, vol. 8, no. 4, pp. 423-443, 2010.

[101] T. Hanai, N. Koizumi, and A. Irimajiri, "A method for determining the dielectric constant and the conductivity of membrane-bounded particles of biological relevance," Biophysics of Structure and Mechanism, vol. 1, no. 4, pp. 285-294, 1975.

[102] T. Hanai, K. Asami, and N. Koizumi, "Dielectric theory of concentrated suspensions of shell-spheres in particular reference to the analysis of biological cell suspensions," Bulletin of the Institute for Chemical Research, Kyoto University, vol. 57, no. 4, 1979.

[103] D. Das, F. A. Kamil, K. Biswas, and S. Das, "Evaluation of single cell electrical parameters from bioimpedance of a cell suspension," RSC Advances, vol. 4, no. 35, pp. 18178-18185, 2014.

[104] J. C. Maxwell, A Treatise on Electricity and Magnetism, Clarendon Press, Oxford, UK, 1873.

[105] M. Apostol, Magnetic and Electric Resonance, Cambridge Scholars Publishing, Tyne, UK, 2018.

[106] The Clausius-Mossotti factor," in Dielectrophoresis, pp. 119-144, John Wiley \& Sons, Hoboken, NJ, USA, 2017.

[107] K. W. Wagner, "Erklärung der dielektrischen Nachwirkungsvorgänge auf Grund Maxwellscher Vorstellungen," Archiv für Elektrotechnik, vol. 2, no. 9, pp. 371-387, 1914.

[108] T. Hanai, "Theory of the dielectric dispersion due to the interfacial polarization and its application to emulsions," Kolloid-Zeitschrift, vol. 171, no. 1, pp. 23-31, 1960.

[109] A. Irimajiri, Y. Doida, T. Hanai, and A. Inouye, "Passive electrical properties of cultured murine lymphoblast (L5178Y) with reference to its cytoplasmic membrane, nuclear envelope, and intracellular phases," The Journal of Membrane Biology, vol. 38, no. 3, pp. 209-232, 1978.

[110] T. Hanai, H. Z. Zhang, K. Sekine, K. Asaka, and K. Asami, "The number of interfaces and the associated dielectric relaxations in heterogeneous systems," Ferroelectrics, vol. 86, no. 1, pp. 191-204, Oct. 1988

[111] M. Takagi and N. Tokunaga, "Noninvasive discrimination between human normal and cancer cells by analysis of intracellular distribution of phase-shift data," Cytotechnology, vol. 67, no. 4, pp. 733-739, Aug. 2015. 
[112] M. Lekka, "Discrimination between normal and cancerous cells using AFM," BioNanoScience, vol. 6, no. 1, pp. 65-80, 2016.

[113] A. R. Lima, A. M. Araújo, J. Pinto et al., "Discrimination between the human prostate normal and cancer cell exometabolome by GC-MS," Scientific Reports, vol. 8, no. 1, pp. 1-12, 2018.

[114] F. E. Giana, F. J. Bonetto, and M. I. Bellotti, "Assay based on electrical impedance spectroscopy to discriminate between normal and cancerous mammalian cells," Physical Review E, vol. 97 , no. 3, p. 32410, 2018. 